\title{
Flora bacteriana aeróbica del tracto digestivo del vampiro común, Desmodus rotundus (Chiroptera: Phyllostomidae)
}

\author{
Gloriana Chaverri \\ Biology Department, Boston University, Boston MA 02215, United States; glori@bu.edu \\ Recibido 09-VI-2003. Corregido 13-XII-2004. Aceptado 07-III-2006.
}

\begin{abstract}
Aerobic bacterial flora from the digestive tract of the common vampire bat, Desmodus rotundus (Chiroptera: Phyllostomidae). This study addresses the composition of microbial flora in the vampire bat (Desmodus rotundus) primarily because all available data are outdated, and because of the economical significance of this bat species. Twenty-one bats were collected and their aerobic bacteria documented separately for stomach and intestine. Bacteria were identified through the Analytical Profile Index (API), and results analyzed with the APILAB software. A total of thirty bacterial species were isolated from sixteen females and five males. The most common species were Escherichia coli and Staphylococcus aureus, although other bacteria, such as Acinetobacter johnsonii, Enterobacter sakazakii, Staphylococcus chromogenes, S. hyicus and S. xylosus were also common. The number of species found in the stomach and intestine was significantly different, and the intestine presented a higher diversity compared to the stomach. This has previously been found in other mammals and it is attributed to a reduction of acidity. Most of the species found in this study are considered normal components of the digestive tract of mammals, although other bacteria common in the skin of mammals and from aquatic environments were found. Bacteria from the skin may invade the vampire's stomach and/or intestine when the bat has contact with its prey, and may suggest that the vampire's feeding habit facilitates the invasion of other microbes not common in its digestive tract. The fact that bacteria from aquatic environments were also found suggests that $D$. rotundus, as previously found by other researchers, drinks free water when available, and water may be another source of microbial invasion. Rev. Biol. Trop. 54 (3): 717-724. Epub 2006 Sept. 29.
\end{abstract}

Key words: aerobic bacteria, vampire, bat, stomach, intestine, digestive tract.

Los murciélagos constituyen un grupo de gran importancia, tanto por su gran diversidad, como por su participación en múltiples interrelaciones ecológicas. Los murciélagos juegan un papel importante como consumidores de insectos y además son depredadores de otros vertebrados, como peces, ranas, aves y mamíferos; son presa de muchas otras especies, como aves rapaces y serpientes; y también son importantes polinizadores y dispersores de semillas (Altringham 1998).

Existe una relación simbiótica muy estrecha entre los murciélagos y gran cantidad de microorganismos. Por ejemplo, las bacterias en el tracto digestivo de los murciélagos ayudan a degradar y digerir los alimentos que estos ingieren (Bull y Slater 1982, Jawetz et al. 1984, Salyers y Shipman 2002), también sintetizan ciertas vitaminas y ayudan a proteger el cuerpo de la invasión de otros microorganismos dañinos (Jawetz et al. 1984, Atlas 1995).

Las bacterias no son microorganismos exclusivos de los murciélagos, y es muy probable que las mismas especies de bacterias se encuentren también en otros mamíferos (Hill y Smith 1984). Sin embargo, a través del tiempo se ha señalado a los murciélagos como importantes portadores de una enorme variedad de microorganismos patógenos (Hill y Smith 1984), y por lo tanto se les ha catalogado como organismos altamente perjudiciales. Si bien es cierto los murciélagos están directamente 
relacionados con la transmisión de enfermedades como la rabia y la histoplasmosis, y aunque en el pasado se han aislado bacterias patógenas en ellos, no hay evidencia concreta de que estas bacterias representen un alto riesgo para la salud humana. Por lo tanto, a excepción de la rabia y la histoplasmosis, los murciélagos parecen jugar sólo un papel marginal en la ecología de las enfermedades patógenas en los humanos (Gaisler 1979), o se conoce poco de su posible participación.

Dentro de Chiroptera, el orden de los murciélagos, el que probablemente tiene más posibilidad de asociarse con la transmisión de organismos patógenos al humano y a los animales domésticos es el vampiro común (Desmodus rotundus), debido principalmente a su hábito alimenticio hematófago. Las tres especies de los llamados vampiros verdaderos tienen una distribución Neotropical (Wimsatt 1986), siendo el llamado vampiro común el más abundante y ampliamente distribuido (Turner 1991). Los vampiros se alimentan de sangre íntegra, y aparentemente prefieren la de los bovinos, ya que ésta se asienta lentamente, se obtiene más fácilmente, y existe una mayor disponibilidad en muchas localidades. Sin embargo, este murciélago puede consumir la sangre de cualquier animal homeotérmico (Wimsatt 1986).

En Brasil y en Perú se ha informado la transmisión de dos bacterias patógenas por $D$. rotundus al hombre, Bartonella y Grahamella, las cuales ocasionan la enfermedad llamada bartonelosis (Baker et al. 1976). La rabia paralítica es otra enfermedad transmitida por los vampiros, siendo en este caso el vector más importante. D. rotundus es considerado plaga en Costa Rica (Hilje y Monge 1988) debido a que ataca animales domésticos. Sin duda alguna, el vampiro común es la especie que más pérdidas ocasiona al hombre (Gaisler 1979), especialmente porque la especie sufrió una explosión poblacional después de que se introdujo el ganado en el Nuevo Mundo, ya que éste se convirtió en una fuente más abundante y segura de alimento que los animales silvestres (Turner 1991). En Costa Rica y Sur América se han registrado pérdidas anuales de hasta US\$100 millones por la muerte de ganado debido a la transmisión de la rabia paralítica (Turner 1991).

El objetivo del presente trabajo es determinar la flora bacteriana aeróbica del tracto digestivo del vampiro común, principalmente por tres razones: la gran importancia económica del vampiro; por la poca y desactualizada literatura sobre este tema en particular; y para justificar la eliminación de mitos sobre esta especie estudiándola a profundidad. Estos estudios eventualmente permitirán realizar más y mejores esfuerzos de conservación para ésta y otras especies de murciélagos.

\section{MATERIALES Y MÉTODOS}

En la determinación de los componentes bacterianos se utilizaron 21 especímenes de $D$. rotundus (16 hembras y cinco machos) recolectándolos en cuatro localidades distintas en Costa Rica de junio a noviembre de 1996. Los especímenes de vampiro común se obtuvieron de las capturas periódicas realizadas en diversas zonas del país como parte del programa de control de la rabia paralítica de los bovinos, que se lleva a cabo por el Departamento de Salud Animal del Ministerio de Agricultura y Ganadería. De los animales considerados, solamente un individuo juvenil no presentaba sangre en su sistema digestivo. Además de este individuo juvenil, se estudiaron también tres hembras preñadas, otra en época de lactancia y un macho en estado reproductivo. Los demás individuos no estaban reproductivamente activos.

Los murciélagos fueron eutanizados colocándolos en una bolsa con éter. Posteriormente se abrieron en la zona ventral con el fin de separar, mediante pinzas estériles, el intestino y el estómago del resto del cuerpo. Una vez separada la porción del tracto digestivo, ésta se bañó en una solución de alcohol absoluto y se flameó para garantizar su esterilidad exterior. Posterior a la esterilización, se procedió a separar mediante un bisturí estéril estómago e intestino, a los cuales se les practicó una pequeña incisión. 
Luego se aplicó directamente la zona expuesta sobre los medios de cultivo bacteriológicos convencionales: agar MacConkey, manitol sal y agar sangre. Con el asa bacteriológica se rayó la muestra en el medio de cultivo según el método de las cuatro estrías (Atlas 1995), con el fin de obtener colonias aisladas. Estos medios se incubaron aeróbicamente a $37^{\circ} \mathrm{C}$ por $48 \mathrm{~h}$. Pasado el tiempo de incubación, se aislaron las bacterianas en cultivo puro para su posterior identificación. Para preservar las colonias aisladas, éstas se sembraron en agar nutritivo inclinado.

Todas las bacterias se separaron en cuatro grupos, basándose en las pruebas bioquímicas y en la tinción de Gram. Las bacterias Gram positivas se separaron en dos grupos: catalasa positivas (estafilococos) y catalasa negativas (estreptococos). Las bacterias Gram negativas se separaron en dos grupos: enterobacterias y no enterobacterias, esto mediante la prueba de oxidasa. Para la identificación final se utilizó el sistema de Analitical Profile Index (API). Para el caso específico de las enterobacterias se utilizó el API 20 E-BioMérieux, para no enterobacterias el API 20 NE- BioMérieux, para estafilococos el API Staph-BioMérieux y para estreptococos el API Rapid Strep-BioMérieux, y se utilizó para procesar los resultados de éstas la base de datos APILAB. En caso de que no se pudieran identificar las bacterias mediante el APILAB, se procedió a hacerlo mediante el manual de bacteriología determinativa de Bergey (Bergey y Holt 1994) y diagnóstico microbiológico (Koneman et al. 1985), utilizando los resultados bioquímicos obtenidos mediante las pruebas API.

Finalmente, se realizó una prueba de $\chi^{2}$ para determinar si ambos sitios, estómago e intestino, difieren significativamente en las especies bacterianas encontradas. Ausencia de una especie bacteriana se denominó con cero, y presencia se identificó como uno.

\section{RESULTADOS}

De un total de 103 aislamientos obtenidos de 21 estómagos y 21 intestinos, se identificaron
30 especies bacterianas aeróbicas (Cuadro 1). Catorce de las especies identificadas se aislaron solamente en el intestino y seis sólo en el estómago, con diez especies comunes en ambos sitios del tracto digestivo. El número de especies encontradas en las dos zonas (estómago e intestino) fue significativamente diferente $\left(\chi^{2}=\right.$ $10.93, \mathrm{p}<.05)$, siendo el intestino más diverso que el estómago. Las bacterias que se encontraron en el estómago pero no en el intestino son: Enterobacter intermedius, Enterococcus faecalis, Flavobacterium meningosepticum, Lactococcus lactis, Staphylococcus haemolyticus y Staphylococcus warneri, y algunas de las bacterias aisladas en el intestino pero ausentes en el estómago son, entre otras, Acinetobacter lwoffii, Aeromonas hydrophila, Enterobacter agglomerans y Proteus mirabilis (Cuadro 1).

Escherichia coli y Staphylococcus aureus fueron las especies más frecuentes, con un $35.9 \%$ del total de aislamientos, mientras que ninguna otra especie representa más del 7.7\% del total de aislamientos obtenidos. Las bacterias que más comúnmente se aislaron en el estómago son S. aureus, E. coli y Staphylococcus hyicus (Fig. 1), y las que se encontraron con más frecuencia en el intestino fueron $E$. coli, $S$. aureus y Staphylococcus xylosus (Fig. 2).

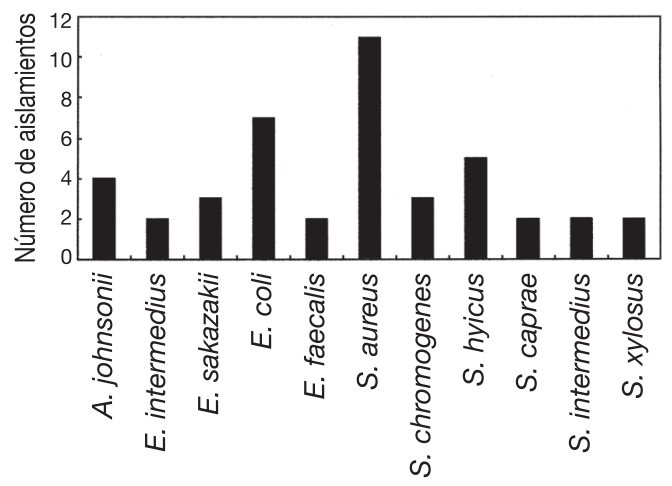

Fig. 1. Especies bacterianas con más de dos aislamientos en el estómago de $D$. rotundus.

Fig. 1. Bacteria isolated more than twice from the stomach of D. rotundus. 
CUADRO 1

Número de aislamientos de las 30 especies de bacterias presentes en el intestino y el estómago de D. rotundus

TABLE 1

Number of isolations of the 30 species of bacteria found in the intestine and stomach of $\mathrm{D}$. rotundus

Grupo Bacteria

Bacilos enterobacterias

Estafilococos

Estreptococos
Enterobacter agglomerans

Enterobacter cloacae

Enterobacter intermedius

Enterobacter sakazakii

Escherichia coli

Hafnia alvei

Proteus mirabilis

Serratia ficaria

Serratia marcescens

Acinetobacter johnsonii

Acinetobacter lwoffii

Aeromonas hydrophila

Aeromonas sobria

Alcaligenes faecalis

Flavimonas oryzihabitans

Flavobacterium meningosepticum

Vibrio parahaemolyticus

Micrococcus varians

Staphylococcus aureus

Staphylococcus caprae

Staphylococcus chromogenes

Staphylococcus epidermidis

Staphylococcus haemolyticus

Staphylococcus hyicus

Staphylococcus intermedius

Staphylococcus warneri

Staphylococcus xylosus

Enterococcus faecalis

Lactococcus lactis lactis

Streptococcus dysgalactiae

Total
Intestino

Estómago

Total

1

0

3

11

1

0

1

2

6

18

1

\section{1}

\section{1}

1

3

3

1

\section{1}

1

1

1

0

0

1

1

8

1

(

3

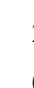

0

3

.

.

0

4

0

$\begin{array}{lll}0 & 1 & 1 \\ 1 & 0 & 1\end{array}$

55
48 


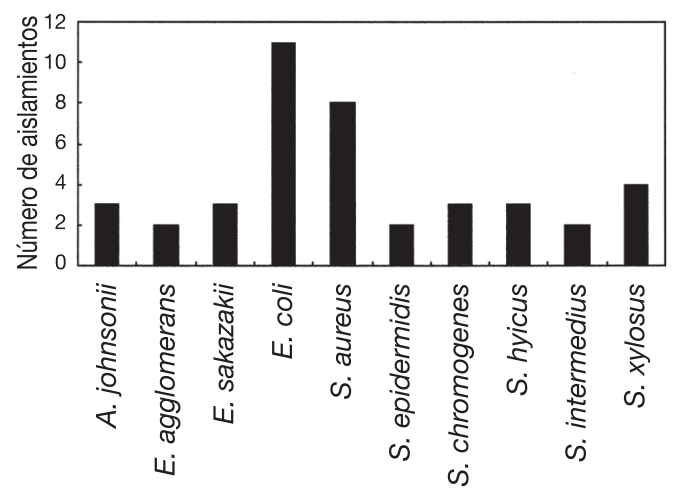

Fig. 2. Especies bacterianas con más de dos aislamientos en el intestino de D. rotundus.

Fig. 2. Bacteria isolated more than twice from the intestine of $D$. rotundus.

\section{DISCUSIÓN}

La mayor riqueza de especies (24, de un total de 30) a nivel intestinal probablemente esté favorecida por una reducción en la acidez. Sin embargo, es importante resaltar que el tracto digestivo de D. rotundus, en comparación con el de otros mamíferos, presenta importantes variaciones morfológicas y fisiológicas. Algunas de estas diferencias, tales como la presencia de un estómago tubular e intestiforme y un tracto intestinal considerado como un único intestino delgado (Mitchel y Tigner 1970, Bhatnagar 1988) probablemente ocasionan una distribución y diversidad microbiana particular a esta especie, a pesar de que algunos autores como Brock et al. (1984) han propuesto que la flora microbiana es muy distinta entre la zona del estómago y la del intestino grueso en otros mamíferos.

La mayor parte de las bacterias aisladas en el tracto digestivo del vampiro se consideran flora normal del tracto digestivo de mamíferos. Tal es el caso de E. coli (Mitscherlich y Marth 1984, Bergey y Holt 1994, Holt et al. 1994) y S. aureus (Holt et al. 1994, Kloos y Bannerman 1995), las cuales han sido también aisladas previamente en el tracto digestivo del vampiro (Moreno et al. 1975, Pinus y Müller 1980). Otras bacterias que se aislaron y que se encuentran normalmente en el tracto digestivo de otros mamíferos son: Acinetobacter spp., Aeromonas sobria, Alcaligenes faecalis, Enterobacter spp., E. faecalis, Hafnia alvei, Proteus spp., Staphylococcus spp., Streptococcus dysgalactiae y Vibrio parahaemolyticus (Mitscherlich y Marth 1984, Facklam y Sahm 1995, Farmer 1995, Isenberg y D'Amato 1995, Kloos y Bannerman 1995).

Muchas de las bacterias aisladas también se encuentran comúnmente en la piel de mamíferos y/o aves. Por ejemplo, S. hyicus se ha aislado previamente en la piel de cerdos (Gilmour y Rowe 1990), Staphylococcus chromogenes y S. xylosus en la piel de vacas y cerdos (Gilmour y Rowe 1990, Murray 1995). Staphylococcus epidermidis es la especie de estafilococo que se encuentra en mayor abundancia en la piel del humano y puede encontrarse en menor grado en la piel de otros mamíferos (Mitscherlich y Marth 1984, Bergey y Holt 1994, Holt et al. 1994). S. warneri es una bacteria muy común en la piel y vías nasales de los primates, y pocas veces se ha logrado aislar de otros animales (Holt et al. 1994). Staphylococcus intermedius se ha aislado principalmente de mamíferos carnívoros, aunque también se ha encontrado en caballos y palomas (Holt et al. 1994). En general, todos los estafilococos son comunes en la piel de diversos mamíferos (Kloos y Bannerman 1995), así que es de esperarse que estas bacterias sean comunes en el tracto digestivo del vampiro, debido primordialmente a su elevado contacto con la piel de sus presas. De las bacterias del género Staphylococcus, S. epidermidis y $S$. aureus han sido anteriormente aisladas en el vampiro común (Moreno et al. 1975).

Otras bacterias que se pueden encontrar en la piel de diversos mamíferos y que fueron aisladas en el presente trabajo son Acinetobacter johnsonii, A. lwoffii y Micrococcus varians (Kloos y Bannerman 1995, Murray 1995). También Acinetobacter puede ser un género encontrado en ambientes de agua dulce, y ya que el vampiro común es capaz de consumir agua libre si está disponible (Busch 1988), entonces se esperaría que muchas de las bacterias de ambientes de agua dulce estén presentes en el tracto digestivo de esta especie. 
Otras bacterias presentes en ambientes dulceacuícolas y que fueron aisladas del tracto digestivo del vampiro son: Aeromonas spp., A. faecalis, Enterobacter spp., E. faecalis, F. meningosepticum, $H$. alvei, $P$. mirabilis, Serratia spp. y $V$. parahaemolyticus (Mitscherlich y Marth 1984, Bergey y Holt 1994, Holt et al. 1994, Facklam y Sahm 1995, Farmer 1995, Janda et al. 1995). De las anteriores bacterias, las que han sido citadas en la literatura como presentes en el tracto del vampiro son Enterobacter cloacae y P. mirabilis (Moreno et al. 1975, Pinus y Müller 1980). Además, aunque $A$. hydrophila es una especie de bacteria que se ha aislado anteriormente con mucha frecuencia en el vampiro, en este trabajo solamente fue aislada una vez. Se cree que esta bacteria juega un papel importante en la digestión de la sangre consumida por el vampiro (Pinus y Müller 1980).

L. lactis lactis es otra bacteria que se logró aislar en el presente estudio. Esta bacteria no parece formar parte de la flora normal del tracto digestivo de ningún animal, no forma parte de hábitat acuáticos, ni tampoco es parte de la flora normal de la piel de ningún animal, y por lo tanto su presencia en el tracto digestivo de uno de los especímenes no es fácil de explicar. L. lactis es una bacteria de origen lácteo, y que podría encontrarse también en productos vegetales (Holt et al. 1994).

Los resultados en el presente trabajo permiten determinar que la mayor parte de las bacterias encontradas en el tracto digestivo de los vampiros estudiados forman parte de la flora bacteriana de otros mamíferos y además se encuentran también en sitios diversos tales como ambientes acuáticos. Esto indica que, a pesar de que el vampiro se ha considerado tradicionalmente como portador de gran cantidad de organismos patógenos, su flora bacteriana está compuesta de bacterias que comúnmente se hallan en otros sitios. Sin embargo, es necesario aún realizar estudios que identifiquen los microorganismos presentes en la saliva del vampiro, para así complementar los datos referentes a su composición microbial y entender mejor si realmente el vampiro representa un peligro en lo que a transmisión de patógenos bacterianos se refiere.

Durante este estudio, también ha sido posible establecer que hay una falta de información actualizada sobre la composición microbiana de un mamífero importante para el humano, como lo es el vampiro común. Por ejemplo, se encontraron especies nunca antes registradas para el vampiro, y también se hallaron bacterias que no se habían aislado antes en otros mamíferos. Sin embargo, todavía es necesario incluir información de bacterias anaerobias, hongos y otros microorganismos, para lograr comprender a profundidad la dinámica microbiana de esta especie. Trabajos más exhaustivos de identificación y zonación microbial probablemente ayudarán a esclarecer aspectos fisiológicos y de comportamiento en ésta y otras especies. Finalmente, trabajos similares a éste pueden ayudar a mejorar los esfuerzos de conservación que se realizan para proteger especies desprestigiadas como el vampiro.

\section{AGRADECIMIENTOS}

Agradezco a L. Castro por su asesoramiento durante esta investigación, y a los laboratorios de Microbiología de la Escuela de Ciencias Biológicas y de Bacteriología de la Escuela de Veterinaria (Universidad Nacional), especialmente a L. Torres, G. Hernández y J. González por su cooperación. Finalmente, a V.H. Sancho por su valioso aporte de especímenes.

\section{RESUMEN}

El objetivo de esta investigación fue determinar la flora bacteriana del vampiro común (Desmodus rotundus) primordialmente debido a que los datos al respecto están desactualizados, y además por la gran importancia económica de esta especie de murciélago. Veintiún murciélagos fueron recolectados y su flora bacteriana identificada separadamente a nivel de estómago e intestino. Las bacterias fueron identificadas con el Analytical Profile Index (API), y los resultados analizados con el paquete APILAB. Un total de treinta especies fueron aisladas en 16 hembras y cinco machos. Las especies más comunes fueron Escherichia coli y Staphylococcus aureus, aunque otras 
especies, como Acinetobacter johnsonii, Enterobacter sakazakii, Staphylococcus chromogenes, S. hyicus y $S$. xylosus también se aislaron con frecuencia. El número de especies identificadas en el estómago y el intestino fue significativamente diferente, siendo el intestino más diverso. Esto ha sido encontrado anteriormente en otros mamíferos, y se atribuye probablemente a la reducción en acidez. Asimismo, la mayoría de las especies identificadas en este estudio forman parte de la flora bacteriana normal del tracto digestivo de mamíferos, aunque también se encontraron otras bacterias comunes en la piel de mamíferos y en ambientes acuáticos Las bacterias de la piel podrían estar colonizando el estómago y/o intestino del vampiro cuando éste tiene contacto con sus presas, lo que sugiere que el hábito alimentario de esta especie facilita su colonización por microorganismos que no se encontrarían comúnmente en su tracto digestivo. Ya que también se identificaron bacterias comunes en ambientes acuáticos, es probable que $D$. rotundus consuma agua cuando esté disponible, lo que respalda los resultados de otros investigadores, y sugiere que esta podría ser una fuente adicional de invasión microbiana.

Palabras clave: bacterias aeróbicas, vampiro, murciélago, estómago, intestino, tracto digestivo.

\section{REFERENCIAS}

Altringham, J.D. 1998. Bats: Biology and Behaviour. Oxford University, Oxford, Inglaterra. 262 p.

Atlas, R.M. 1995. Principles of Microbiology. Mosby, St. Louis, Misuri, EEUU. 888 p.

Baker, R.J., J.K. Jones \& D.C. Carter. 1976. Biology of bats of the New World family Phyllostomatidae. Texas Tech, Lubbock, Texas, EEUU. 3 p.

Bergey, D.H. \& J.G. Holt. 1994. Bergey's Manual of Determinative Bacteriology. Williams \& Wilkins, Baltimore, Maryland, EEUU. 787 p.

Bhatnagar, K.P. 1988. Anatomy, p. 41-70. In A.M. Greenhall \& U. Schmidt (eds.). Natural History of Vampire Bats. CRC, Boca Ratón, Florida, EEUU.

Brock, T.D., D.W. Smith \& M.T. Madigan. 1984. Biology of Microorganisms. Prentice Hall, Englewood Cliffs, Nueva Jersey, EEUU. 847 p.

Bull, A.T. \& J.H. Slater. 1982. Microbial interactions and community structure, p. 13-44. In A.T. Bull \& J.H. Slater (eds.). Microbial Interactions and Communities. Academic, Londres, Inglaterra.

Busch, C. 1988. Consumption of blood, renal function and utilization of free water by the vampire bat, Desmodus rotundus. Comp. Biochem. Physiol. 90: 141-146.
Facklam, R.R. \& D.F. Sahm. 1995. Enterococcus, p. 308314. In P.R. Murray, E.J. Baron, M.A. Pfaller, F.C. Tenover \& R.H. Yolken (eds.). Manual of Clinical Microbiology. ASM, Washington D.C., EEUU.

Farmer, J.J.I. 1995. Enterobacteriaceae: introduction and identification, p. 438-449. In P.R. Murray, E.J. Baron, M.A. Pfaller, F.C. Tenover \& R.H. Yolken (eds.). Manual of Clinical Microbiology. ASM, Washington D.C., EEUU.

Gaisler, J. 1979. Ecology of bats, p. 281-342. In D.M. Stoddart (ed.). Ecology of Small Mammals. Chapman and Hall, Londres, Inglaterra.

Gilmour, A. \& M.T. Rowe. 1990. Micro-organisms associated with milk, p. 37-75. In R.K. Robinson (ed.). Dairy Microbiology: the Microbiology of Milk. Elsevier Applied Science, Londres, Inglaterra.

Hilje, L. \& J.E. Monge. 1988. Lista preliminar y consideraciones generales acerca de los animales vertebrados plaga en Costa Rica. Manejo Integrado de Plagas 22: $39-52$.

Hill, J.E. \& J.D. Smith. 1984. Bats: a natural history. University of Texas, Austin, Texas, EEUU. 243 p.

Holt, J.G., N.R. Krieg, P.H.A. Sneath \& J.T. Staley. 1994. Bergey's Manual of Determinative Bacteriology. Williams \& Wilkins, Baltimore, Maryland, EEUU. $787 \mathrm{p}$.

Isenberg, H.D. \& R.F. D’Amato. 1995. Indigenous and pathogenic microorganisms of humans, p. 5-18. In P.R. Murray, E.J. Baron, M.A. Pfaller, F.C. Tenover \& R.H. Yolken (eds.). Manual of Clinical Microbiology. ASM, Washington D.C., EEUU.

Janda, J.M., S.L. Abbott \& A.M. Carnahan. 1995. Aeromonas and Plesiomonas, p. 477-482. In P.R. Murray, E.J. Baron, M.A. Pfaller, F.C. Tenover \& R.H. Yolken (eds.). Manual of Clinical Microbiology. ASM, Washington D.C., EEUU.

Jawetz, E., J.L. Melnick \& E.A. Adelberg. 1984. Review of Medical Microbiology. Lange Medical, Los Altos, California, EEUU. 557 p.

Kloos, W.E. \& T.L. Bannerman. 1995. Staphylococcus and Micrococcus, p. 282-298. In P.R. Murray, E.J. Baron, M.A. Pfaller, F.C. Tenover \& R.H. Yolken (eds.). Manual of Clinical Microbiology. ASM, Washington D.C., EEUU.

Koneman, E., S.D. Allen, V.R. Dowell \& H.M. Sommers. 1985. Diagnóstico Microbiológico. Médica Panamericana, México, D.F. 533 p.

Mitchel, G.C. \& J.R. Tigner. 1970. The route of ingested blood in the vampire bat. J Mammal 51: 814-817. 
Mitscherlich, E. \& E.H. Marth. 1984. Microbial Survival in the Environment. Springer-Verlag, Berlín. 802 p.

Moreno, G., C.A.M. Lopes, E. Seabra, C. Pavan \& A. Correa. 1975. Bacteriological study of the intestinal flora of Desmodus rotundus. Arq. Inst. Biol. São Paulo 42: 229-232.

Murray, P.R. 1995. Manual of clinical microbiology. ASM, Washington D.C., EEUU. 1482 p.

Pinus, M. \& H.E. Müller. 1980. Enterobacteria of bats. Zbl. Bakt. Hyg., I. Abt. Orig. 247: 315-322.
Salyers, A.A. \& J.A. Shipman. 2002. Getting in touch with your prokaryotic self: mammal-microbe interactions, p. 315-341. In J.T. Staley \& A.-L. Reysenbach (eds.). Biodiversity of Microbial Life. Wiley-Liss, Nueva York, EEUU.

Turner, D.C. 1991. Desmodus rotundus, p. 480-482. In D.H. Janzen (ed.). Historia Natural de Costa Rica. Editorial de la Universidad de Costa Rica, San José.

Wimsatt, W.A. 1986. Vampire bats, p. 644-649. In M.E. Fowler (ed.). Zoo and Wild Animal Medicine. Saunders, Filadelfia, Pensilvania, EEUU. 